\title{
A esperança impulsiona, alimenta, move e fortalece a utopia
}

Maria Lucia Frizon Rizzotto1,2, Ana Maria Costa1,3, Lenaura de Vasconcelos Costa Lobato1,4

DOI: $10.1590 / 0103-1104202012700$

ESTE EDITORIAL, QUE ENCERRA AS NOSSAS ATIVIDADES DE 2020, não poderia ter outro tom que não fosse de tristeza e indignação. Aproximamo-nos de 200 mil mortes decorrentes da Covid-19, com franca elevação do número de casos e óbitos desde outubro e dramática previsão de aumento para os primeiros meses do ano vindouro em virtude das aglomerações de final de ano. $\mathrm{O}$ povo brasileiro segue entregue ao vírus sem que medidas adequadas e oportunas por parte do governo federal sejam adotadas para salvar vidas. O editorial' ${ }^{1}$ da revista 'The Lancet', de maio de 2020, alertou sobre os riscos sanitários para o País decorrentes da má condução da crise atribuída ao governo federal deixando que o vírus circulasse livremente e ganhasse o território nacional. Esse editorial, intitulado 'So What?', repete uma frase do presidente, que, quando interpelado sobre as mortes e a pandemia, respondeu, chocando o mundo: $E$ daí?

Na mesma direção, o editorial ${ }^{2}$ da revista 'Saúde em Debate', de junho de 2020, adverte sobre a ausência de um plano nacional de enfrentamento da pandemia, obrigando estados e municípios a agirem sem coordenação e apoio do governo federal. Propostas e estratégias racionais, fundamentadas em conhecimento científico, foram desconsideradas, sendo substituídas por discurso ideológico que promoveu o negacionismo, com repercussão negativa nas medidas de prevenção como uso de máscaras e distanciamento social, além de 'prescrever' e divulgar falsas ilusões terapêuticas sobre as quais ainda não se dimensionaram os malefícios no curso da pandemia e da doença.

A farta produção científica que o Brasil vem divulgando acerca da pandemia e as suas circunstâncias de enfrentamento apontam que grande parte das mortes poderia ter sido evitada se tivéssemos vontade política e adotado as medidas consequentes e eficazes. Infelizmente, esta pandemia encontrou a República do Brasil presidida por uma pessoa despreparada para o cargo, sem empatia e insensível à dor das milhares de pessoas que perderam entes queridos, amigos, colegas de trabalho e companheiros. Para além desse perfil do presidente, o conjunto de seu governo vem se aproveitando do sofrimento do povo para aplicar medidas perversas de uma política econômica que esvazia as chances de um Estado soberano e com justiça social. Ao lado disso, esse governo e suas alianças promovem a mais danosa política ambiental e a escolha de um caminho isolado nas relações internacionais, em especial neste momento de extrema necessidade e dependência de tecnologias e insumos para o controle do novo coronavírus. O governo não é só incompetente em administrar o País na pior crise sanitária de nossa história. Ele trabalha contra os interesses das e dos brasileiros, deixando mortos pelo caminho, mentindo e fazendo descaso do sofrimento e aprofundando as condições de

\footnotetext{
${ }^{1}$ Centro Brasileiro de Estudos de Saúde (Cebes) - Rio de Janeiro (RJ), Brasil. frizon@terra.com.br

2 Universidade Estadual do Oeste do Paraná (Unioeste) - Cascavel (PR), Brasil.

${ }^{3}$ Escola Superior de Ciências da Saúde (ESCS) - Brasília (DF), Brasil.

4 Universidade Federal Fluminense (UFF) - Niterói (RJ), Brasil.
} 
pobreza, com uma política econômica austericida que reduz o investimento público, considerado um modelo de política tosca, antiquada e de ineficácia comprovada em todo o mundo, mesmo entre teóricos conservadores.

O presidente que se elegeu prometendo uma nova política atua da forma mais atrasada no conluio com o 'centrão', à custa de poderosas transações e com o dinheiro público que ele afirma não ter para combater o vírus e estender o auxílio emergencial.

Ao encerrar o ano, destacamos o trabalho realizado pelo Centro Brasileiro de Estudos de Saúde (Cebes) neste momento tão desafiador, especialmente para as entidades da luta pela Reforma Sanitária. Em meio às diversas mobilizações e posicionamentos públicos, o Cebes se articulou com dezenas de entidades do campo da saúde para formar a Frente pela Vida, a qual, diante da visível ausência de um plano de enfrentamento da pandemia, mobilizou estudiosos de todas as disciplinas para elaborar o Plano Nacional de Enfrentamento à Pandemia da Covid-1933, oferecendo-o ao governo federal e aos governos das instâncias subnacionais como contribuição das entidades da Reforma Sanitária.

No plano editorial, publicamos, além dos números regulares, diversos números especiais da revista 'Saúde em Debate', sendo um deles dedicado ao tema da pandemia. No campo político, o Cebes tem atuado no Congresso Nacional para garantir financiamento adequado ao Sistema Único de Saúde (SUS) combatendo a EC-95 que congelou o investimento público por 20 anos, o que significa a pá de cal no projeto do SUS-Constitucional, ou seja, universal, integral e resolutivo. Nossas preocupações se voltam agora não apenas ao agravamento da pandemia, mas também para a ausência de garantias de vacinas suficientes para imunizar a nossa população.

Nesse turbilhão de ativismo e formulação de propostas, avançamos ainda mais criando o Cebes Debate, um canal com programação sobre os temas importantes para a conjuntura e para a saúde, direcionado a todo o público, além de programas de debates internos entre os núcleos regionais ou temáticos que integram o Cebes. Toda a nossa luta esse ano converge para o combate à pandemia e para o fortalecimento do SUS, que, apesar de subfinanciado, está fazendo a diferença e salvando vidas.

Mergulhados neste caos político e administrativo de cunho genocida, não podemos deixar de celebrar a resistência, com quem contamos para sairmos dessa crise abissal. Mais que nunca, é imprescindível reafirmar e valorizar que não estamos sós nomeando e homenageando aqueles que lutam e trabalham pela vida e pelos valores da solidariedade humana.

Saudamos nossos cientistas que trabalham dia e noite para encontrar uma vacina que consiga proteger a população e interromper a transmissão do vírus;

Homenageamos nossos milhões de trabalhadores da saúde que, mesmo cansados e esgotados pelas longas jornadas e pelo estresse que sofrem cotidianamente, continuam à frente desta guerra contra o vírus, mesmo sabendo que isso pode lhes custar a vida;

Celebramos nossos pesquisadores que em suas áreas buscam estudar e compreender a realidade brasileira e oferecer soluções para nossos problemas;

Manifestamos nosso respeito aos milhares de profissionais e servidores públicos que se dedicam a atender a população nos serviços públicos - na saúde, na assistência, na educação, na previdência -, a despeito do desprezo do governo pelo seu trabalho;

Nossa admiração e solidariedade aos milhares de professores que se dedicam a fazer com que as crianças e os jovens sofram menos com o distanciamento social;

Celebramos a solidariedade entre as famílias que se unem para enfrentar o sofrimento pelas perdas e as dificuldades financeiras diante do desemprego e da falta de apoio do governo;

Renascem nossas esperanças com as associações, os movimentos sociais, os movimentos de bairro, que têm desempenhado papel crucial no apoio concreto às famílias e comunidades, na 
organização da resistência aos desmandos do governo federal e de governantes ausentes no atendimento às demandas da população;

A presença da arte na humanidade é essencial, e a produção artística opera como registro subjetivo revelando os sentimentos diante da realidade. Nas palavras de Adorno ${ }^{4(154), ~ " o ~ c o n-~}$ teúdo de verdade das obras de arte funde-se com o seu conteúdo crítico", um conteúdo que não se encontra "fora da história, mas constitui a sua cristalização nas obras".

$\mathrm{Na}$ diversidade das manifestações artísticas, artistas de todas as artes têm registrado os tempos de recolhimento e quarentena provocados pela pandemia em todo o mundo. Em um esforço de iluminar nossa resistência e o otimismo da vontade necessário para temperar o elevado pessimismo da razão desses tempos, trazemos poetas que representaram em verso e em prosa este momento de dor e sofrimento da humanidade, zelando também pela esperança de justiça que haveremos de conquistar.

Moraes Moreira ${ }^{5}$, instigante compositor de músicas e excelente letrista que perdemos no ano de 2020, publicou sua última obra, o cordel 'Quarentena', que além de expressar sobre o medo do vírus, critica e denuncia outras mazelas passadas e presentes do Brasil.

Eu temo o coronavirus e zelo por minha vida, mas tenho medo de tiros também de bala perdida... eu digo não ao machismo também a misoginia, tem outros que eu não aceito é o tal do preconceito e as sombras da hipocrisia...

Que as mensagens dos poetas nos contaminem e nos fortaleçam neste ano novo que certamente exigirá luta e resistência de todos e todas nós; afinal, em tempos de crises, de cólera, de ódio e de intolerância, são fundamentais coragem, ação e utopia.

Concluímos este editorial com o coração pleno de esperança de que o processo civilizatório assuma o curso da construção de um mundo melhor, citando o poema 'Esperanza' do cubano Alexis Valdés ${ }^{6}$, escrito no decorrer da pandemia.

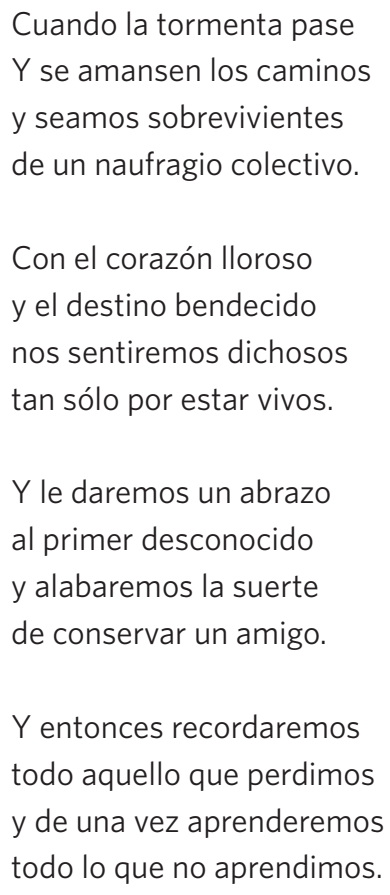


Ya no tendremos envidia pues todos habrán sufrido. Ya no tendremos desidia Seremos más compasivos.

Valdrá más lo que es de todos Que lo jamas conseguido Seremos más generosos

Y mucho más comprometidos

Entenderemos lo frágil

que significa estar vivos

Sudaremos empatía

por quien está y quien se ha ido.

Extrañaremos al viejo

que pedía un peso en el mercado,

que no supimos su nombre

y siempre estuvo a tu lado.

Y quizás el viejo pobre era tu Dios disfrazado.

Nunca preguntaste el nombre

porque estabas apurado.

Y todo será un milagro

Y todo será un legado

Y se respetará la vida,

la vida que hemos ganado.

Cuando la tormenta pase

te pido Dios, apenado,

que nos devuelvas mejores,

como nos habías soñado.

\section{Colaboradoras}

Rizzotto MLF (0000-0003-3152-1362)*, Costa AM (0000-0002-1931-3969)* e Lobato LVC (0000-0002-2646-9523)* contribuíram igualmente para a elaboração do manuscrito. 


\section{Referências}

1. The Lancet. COVID-19 in Brazil: "So what?". Lancet. 2020; (395):1461.

2. Costa AM, Rizzotto MLF, Lobato LVC. Na pandemia da Covid-19, o Brasil enxerga o SUS. Saúde debate [internet]. 2020 [acesso em $2021 \mathrm{fev} \mathrm{17];}$ 44(125):289-296. Disponível em: http://www.scielo.br/scielo.php?script=sci_arttext\&pid=S0103$-11042020000200289 \& \operatorname{lng}=$ en $\& n r m=$ iso.

3. Frente Pela Vida. Plano Nacional de Enfrentamento à Pandemia da Covid-19 [internet]. [acesso em 2021 fev 17]. Disponível em: https://frentepelavida.org.br/uploads/documentos/PEP-COVID-19COMPLETO.pdf.
4. Adorno TW. Teoria Estética. Lisboa: Edições 70; 1970.

5. Moreira M. Cordel Quarentena [internet]. São Paulo: Casal Mala; 2020 [acesso em 2021 fev 17]. Vídeo: 2:27 min. Disponível em: https://www.youtube.com/watch?v=aXSU-zkPoFU.

6. Valdés A. "Esperanza" [internet]. Miami: Alexis Valdes Real; 2020 [acesso em 2021 fev 17]. Vídeo: 2:13 min. Disponível em: https://www.youtube. com/watch?v=p-qgBTHqZk4\&feature=emb_logo. 